ECOLOGICA, Vol. 28, No 102 (2021), 325-330

https://doi.org/10.18485/ecologica.2021.28.102.26

Originalni naučni rad

UDC: 504.5

\title{
Procena ekološkog rizika usled prisustva organskih UV filtera u vodi i sedimentima
}

\section{Environmental risk assessment due to the presence of organic UV filters in water and sediments}

\author{
Jelena Lukić ${ }^{1 *}$, Sara Rvovićn ${ }^{2}$ Tatjana Đurkić ${ }^{3}$, Antonije Onjia ${ }^{4}$ \\ ${ }^{1}$ Inovacioni centar Tehnološko-metalurškog fakulteta, Karnegijeva 4, Beograd, Srbija / \\ Innovation Center of the Faculty of Technology and Metallurgy, Karnegijeva 4, Belgrade, Serbia \\ 2,3,4Univerzitet u Beogradu, Tehnološko-metalurški fakultet, Karnegijeva 4, Beograd, Srbija / \\ University of Belgrade, Faculty of Technology and Metallurgy, Karnegijeva 4, Belgrade, Serbia \\ ${ }^{*}$ Autor za prepisku / Corresponding author
}

Rad primljen / Received: 20.12.2020, Rad prihvaćen / Accepted: 16.05.2021.

Sažetak: Glavni sastojci proizvoda za zaštitu kože od UV zračenja jesu UV filteri. U poslednjih nekoliko godina, organski UV filteri izazvali su značajnu zabrinutost zbog stalnog korišćenja, upornog unosa i potencijalne pretnje ekološkom okruženju i ljudskom zdravlju. Mnogobrojne studije upozoravaju na stabilnost, bioakumulativnost, kao i toksične efekte ovih jedinjenja na akvatične organizme. Procena ekološkog rizika usled prisustva odabranih UV filtera u vodi i sedimentima je vršena na osnovu podataka iz literature vezanih za rezultate monitoringa ovih supstanci, kao i na osnovu podataka o njihovoj toksičnosti po vodene organizme. Najviše koncentracije odabranih organskih UV filtera detektovane su u otpadnim vodama, kao i na mestima ispusta otpadne vode u recipijent. Procena rizika je pokazala da ova jedinjenja predstavljaju potencijalnu pretnju za organizme koji žive u vodenoj sredini. Analizom podataka sa većeg broja lokacija utvrđen je visok ekološki rizik usled prisustva pojedinih UV filtera u vodenoj sredini, i pokazano da su posebno ugrožene lokacije u blizini ispusta otpadnih voda.

Ključne reči: UV filteri, ekološki rizik, toksičnost.

\begin{abstract}
The main ingredients of skin protection products from UV radiation are UV filters. In the last few years, organic UV filters have caused significant concern due to constant use, persistent intake, and potential threats to the environment and human health. Numerous studies warn of the stability, bioaccumulation, as well as toxic effects of these compounds on aquatic organisms. The environmental risk assessment of UV filters was performed based on data from the literature related to the results of monitoring of these substances in water and sediments, as well as based on data on their toxicity to aquatic organisms. The highest concentrations of selected organic UV filters were detected in wastewater, as well as at the points of wastewater discharge into the recipient. Risk assessment has shown that these compounds pose a potential threat to aquatic organisms. The analysis of data from several locations determined a high environmental risk due to the presence of certain UV filters in the aquatic environment and showed that the locations near the wastewater discharge are particularly endangered.
\end{abstract}

Keywords: UV filters, ecological risk, toxicity.

\footnotetext{
${ }^{1}$ orcid.org/0000-0001-9630-9309, e-mail: jlukic@tmg.bg.ac.rs

${ }^{2}$ orcid.org/0000-0001-7089-5311,

2orcid.org/0000-0003-1996-6676, e-mail: tanjav@tmf.bg.ac.rs

2orcid.org/0000-0002-5694-7960, e-mail: onjia@tmf.bg.ac.rs
} 


\section{UVOD / INTRODUCTION}

Organski UV filteri su fotoaktivne supstance koje se koriste u brojnim proizvodima kako bi se umanjili štetni efekti od UV zračenja, čija upotreba se neprestano povećava. Pored toga što služe kao aktivni sastojci u kremama i sprejevima za zaštitu od Sunčevog zračenja, organski UV filteri se koriste i u drugim proizvodima za svakodnevnu upotrebu, poput šampona, losiona nakon brijanja, lakova za nokte, regeneratora i pudera. Takođe, često se nalaze u plastičnim oblogama za hranu, kako bi se poboljšalo očuvanje hrane i koriste se u procesima povezanim sa farmaceutskom i agrohemijskom proizvodnjom (Bratkovics i sar. 2015). Direktan unos UV filtera u prirodne vodene sisteme moguć je spiranjem sa kože u toku rekreativnih aktivnosti, plivanja i kupanja na bazenima i otvorenim kupalištima (netačkasti izvori), kao i pražnjenjem otpadne vode iz industrijskih sistema i indirektnim otpuštanjem (npr. tokom tuširanja, pranja odeće ili ekskrecijom urina) kroz otpadne vode iz domaćinstava (tačkasti izvori) (Santos i sar. 2012). U poslednjih nekoliko godina, organski UV filteri izazvali su značajnu zabrinutost zbog stalnog korišćenja, konstantnog unosa u životnu sredinu i potencijalne pretnje ekološkom okruženju i ljudskom zdravlju. Brojne studije (Carve i sar. 2020) upozoravaju na stabilnost, bioakumulativnost, kao i toksične efekte ovih jedinjenja na akvatične organizme.

Rastuća zabrinutost zbog uticaja UV filtera na životnu sredinu povećala je broj studija ovih supstanci poslednjih godina. Koncentracije UV filtera u životnoj sredini variraju, od $1 \mathrm{ng} / \mathrm{L}$ do $400 \mathrm{mg} / \mathrm{L}$, u zavisnosti od lokacije na kojoj je vršeno uzorkovanje, godišnjeg doba, fizičko-hemijskih osobina supstanci koje se mere i sl. (Ramos i sar. 2016). Zbog svoje lipofilne prirode (vrednost log Kow između 4 i 8) i velike stabilnosti u životnoj sredini, ova jedinjenja se lako mogu akumulirati i biomagnifikovati, dostižući nekoliko trofičnih nivoa. Utvrđeno je da pojedini UV filteri imaju faktore bioakumulacije u ribama veće od 5000 (GagoFerrero i sar., 2012). UV filteri su otkriveni u različitim vodenim organizmima, uključujući ribe, školjke i delfine, kao i u ljudskim tečnostima i tkivima, poput majčinog mleka i placente (Cunha i sar. 2018).

Procena ekološkog rizika (engl. ecological risk assessment, ERA) predstavlja postupak kojim se procenjuje verovatnoća da se već javljaju ili se mogu javiti štetni (neželjeni) ekološki efekti kao rezultat izloženosti receptora iz okruženja jednom ili većem broju stresora. Procena se vrši na osnovu podataka iz literature, vezanih za rezultate monitoringa ovih supstanci, kao i na osnovu terenskih ispitivanja i testova toksičnosti. Procenom ekoloških efekata utvrđuje se veza između koncentracije zagađujućih materija i intenziteta neželjenog uticaja na receptore, na osnovu koje se može utvrditi koja doza izaziva neželjene efekte (Radomirović i sar, 2020).

U ovom radu izvršena je procena ekološkog rizika usled prisustva odabranih organskih UV filtera u uzorcima površinskih i otpadnih voda, kao i sedimenata. Odabrani su UV filteri koji su najzastupljeniji u kozmetičkim preparatima: derivati benzofenona (BP1, BP3, BP4 i 4HB), p-aminobenzoeve kiseline (OD-PABA), kamfora (4-MBC), salicilata (HMS, EHS), cinamata (EHMC, IAMC) i krilena (OC). Pošto imaju različite hemijske strukture i shodno tome, različita fizičko-hemijska svojstva, koja će odrediti njihovu sudbinu u životnoj sredini, očekuje se da će se u vodenim sredinama naći jedinjenja sa velikom rastvorljivošću u vodi, ali i ona sa niskom rastvorljivošću i visokim koeficijentom raspodele oktanol-voda u sedimentima ili zemljištima (Capela i sar. 2019). Procena ekološkog rizika je vršena na osnovu podataka iz literature, vezanih za rezultate monitoringa ovih supstanci u akvatičnoj sredini, kao i na osnovu podataka o njihovoj toksičnosti po vodene organizme.

\section{MATERIJALI I METODE / MATERIALS AND METHODS}

Koeficijent rizika (engl. risk quotients, $R Q$ ) se izračunava kao odnos maksimalno izmerenih koncentracija UV filtera u životnoj sredini (engl. maximum environmental concentration, MEC) i predviđenih koncentracija bez efekata (engl. predicted no effect concentration, PNEC).

$$
\mathrm{RQ}=\mathrm{MEC} /(\mathrm{PNEC})
$$

Nivo ekološkog rizika se na osnovu vrednosti RQ svrstava u 3 kategorije (Wu i sar., 2017):

$\mathrm{RQ} \leq 0,1$ nizak ekološki rizik,

$0,1<\mathrm{RQ}<1$ umeren ekološki rizik,

$R Q>1$ visok ekološki rizik.

Osnova toksikološke i ekotoksikološke karakterizacije je u laboratorijskim studijama (Tanić i sar. 2018, Lukić i sar. 2020), ali se usled nedovoljnog broja podataka prilikom procene ekološkog rizika sve češće upotrebljavaju AF pristup (engl. assessment factor) i SSD (engl. species sensitivity distribution) model. Ova dva modela služe za izračunavanje predviđenih koncentracija bez efekata. Uopšteno govoreći, SSD model predstavlja pouzdaniji način izračunavanja PNEC vrednosti, međutim usled nedovoljno podataka o toksičnosti pojedinih supstanci u cilju maksimalne zaštite ekosistema češće se primenjuje AF model. Ovaj model je iskorišćen prilikom određivanja PNEC vrednosti u slatkoj i morskoj vodi (Carve i sar., 2020). Kada je u pitanju prisustvo stresora u sedimentima, PNEC vrednosti su računate prema jednačini 2 (NORMAN, 2021): 
PNEC $=$ PNECfw $\times 2,6 \times(0,615+0,019 \times \mathrm{Koc}) \quad(2)$ gde je PNECfw vrednost PNEC za slatku vodu, a Koc koeficijent raspodele organski ugljenik-voda. U tabeli 1 prikazane su vrednosti koeficijenta raspode- le organski ugljenik-voda (Koc) odabranih UV filtera na osnovu kog se vrši izračunavanje PNEC vrednosti za sediment. Izračunate PNEC vrednosti, kao i vrednosti iz literature koje su korišćene u ovom radu prilikom procene rizika, prikazane su u tabeli 2 .

Tabela 1-Vrednosti koeficijenta Koc odabranih UV filtera

Table 1- Koc value of selected UV filters

\begin{tabular}{|l|c|c|}
\hline \multicolumn{2}{|c|}{ Organski UV filteri } & Koc $^{*}$ \\
\hline Benzofenon 1 & BP1 & 1077 \\
\hline Benzofenon 2 & BP2 & 7726 \\
\hline Benzofenon 3 & BP3 & 1268 \\
\hline Benzofenon 4 & BP4 & 92,37 \\
\hline 4- hidroksi benzofenon & 4HB & 1745 \\
\hline Oktil dimetil-4-aminobenzoeva kiselina & OD-PABA & 2412 \\
\hline 4-metilbenziliden kamfor & 4-MBC & $1,221 \times 10^{4}$ \\
\hline Homometil salicilat & HMS & $1,076 \times 10^{4}$ \\
\hline Etilheksil salicilat & ES & 8562 \\
\hline Oktil-metoksicinamat & EHMC & 4059 \\
\hline Izoamil p-metoksicinamat & IAMC & 1784 \\
\hline Oktokrilen & OC & $4,113 \times 10^{5}$ \\
\hline Avobenzon & AVO & 1705 \\
\hline
\end{tabular}

*(US Environmental Protection Agency's EPISuite $\left.{ }^{\mathrm{TM}}, 2021\right)$

Tabela 2 - PNEC vrednosti za odabrane organske UV filtere.

Table 2 - PNEC value of selected UV filters

\begin{tabular}{|c|c|c|c|}
\hline \multirow{2}{*}{ Organski UV filteri } & \multicolumn{2}{|c|}{$\begin{array}{c}\text { PNEC }(\mu \mathrm{gg} / \mathrm{L}) \text { vrednost dobijena AF metodom } \\
\text { (Carve et al., 2020) }\end{array}$} & PNEC $(\mu \mathrm{g} / \mathrm{g})$ \\
\cline { 2 - 4 } & Slatka voda & Morska voda & Sediment \\
\hline BP1 & 0,28 & 0,22 & 0,1670 \\
\hline BP2 & 0,67 & 0,17 & 0,2568 \\
\hline BP3 & 19,1 & 0,07 & 0,0989 \\
\hline BP4 & 380 & n.d. & 0,0217 \\
\hline 4-MBC & 2,0 & n.d. & 0,0847 \\
\hline EHMC & 0,40 & 0,30 & 0,0263 \\
\hline OC & 3,18 & 0,40 & 0,0569 \\
\hline AVO & 1,95 & n.d. & 0,1676 \\
\hline IAMC & $0,69^{a}$ & n.d. & 0,0619 \\
\hline ES & $0,26^{a}$ & n.d. & 0,1104 \\
\hline OD-PABA & $0,3^{a}$ & n.d. & 0,0362 \\
\hline \multicolumn{2}{|c|}{ a (NORMAN, 2021). } \\
\hline
\end{tabular}

\section{REZULTATI I DISKUSIJA / RESULTS AND DISCUSSION}

Procena ekološkog rizika od strane prisustva odabranih organskih UV filtera izvršena je na osnovu dosadašnjih istraživanja u kojima su određivane koncentracije UV filtera u rečnoj, jezerskoj, morskoj i otpadnoj vodi kao i sedimentima. $U$ tabeli 3 date su izračunate vrednosti koeficijenata rizika usled prisustva UV filtera u vodi.

U uzorku vode 1 sa jezera Cospuden u Nemačkoj (Moeder i sar., 2010) izračunate RQ vrednosti ukazuju na visok ekološki rizik usled prisustva EHMC, OC i ES (RQ od 1,38 do 7,52). Ove vrednosti se mogu objasniti činjenicom da je uzorkovanje vode vršeno u letnjem periodu kada se na ovoj lokaciji održavaju brojne aktivnosti poput plivanja i različitih vidova rekreacije, pri čemu ova tri UV filtera predstavljaju najčešću kombinaciju UV filtera u kremama za zaštitu od Sunčevog zračenja.

Uzorci 2 i 3 uzorkovani su sa iste lokacije na reci Haungpu u Kini (Wu i sar., 2018). Uzorak broj 2 uzorkovan je u junu, a uzorak broj 3 u oktobru mesecu. Viši ekološki rizik zabeležen je u letnjem periodu i to pokazuje da je važno vreme uzorkovanja kada se vrši studija ekološkog rizika. 
Tabela 3 - Ekološki rizik usled prisustva UV filtera u vodi i sedimentu

Table 3 - Environmental risk due to the presence of UV filters in wáter and sediment

\begin{tabular}{|c|c|c|c|c|c|}
\hline $\begin{array}{c}\text { Broj } \\
\text { uzorka }\end{array}$ & UV filteri & Matrica & $\begin{array}{c}\text { Koncentracija } \\
{[\mu \mathrm{g} / \mathrm{L}]}\end{array}$ & Ref. & $\mathrm{RQ}$ \\
\hline \multirow{6}{*}{1} & BP3 & \multirow{6}{*}{ Jezerska voda } & 0,040 & \multirow{6}{*}{$\begin{array}{l}\text { (Moeder i sar., } \\
\text { 2010) }\end{array}$} & $2,1 \times 10^{-3}$ \\
\hline & IAMC & & 0,146 & & 0,21 \\
\hline & 4-MBC & & 1,140 & & 0,57 \\
\hline & $\mathrm{OC}$ & & 4,381 & & 1,38 \\
\hline & EHMC & & 3,009 & & 7,52 \\
\hline & ES & & 0,748 & & 2,88 \\
\hline \multirow{4}{*}{2} & BP1 & \multirow{4}{*}{ Rečna voda } & 0,559 & \multirow{4}{*}{$\begin{array}{l}\text { (Wu i sar., } \\
\text { 2018) }\end{array}$} & 2,00 \\
\hline & BP2 & & 0,076 & & 0,11 \\
\hline & BP3 & & 5,010 & & 0,26 \\
\hline & BP4 & & 0,088 & & $2,32 \times 10^{-4}$ \\
\hline \multirow{4}{*}{3} & BP1 & \multirow{4}{*}{ Rečna voda } & 0,013 & \multirow{4}{*}{ (Wu i sar. 2017) } & 0,05 \\
\hline & BP2 & & 0,035 & & 0,05 \\
\hline & BP3 & & 0,030 & & $1,57 \times 10^{-3}$ \\
\hline & BP4 & & 0,131 & & $3,45 \times 10^{-4}$ \\
\hline \multirow{4}{*}{4} & BP1 & \multirow{4}{*}{ Rečna voda } & 13 & \multirow{4}{*}{$\begin{array}{l}\text { (Kasprzyk- } \\
\text { Hordern i sar., } \\
\text { 2009) }\end{array}$} & 46,43 \\
\hline & BP2 & & 26 & & 38,81 \\
\hline & BP3 & & 44 & & 2,30 \\
\hline & BP4 & & 323 & & 0,85 \\
\hline \multirow{8}{*}{5} & BP1 & \multirow{8}{*}{ Otpadna voda } & 0,155 & \multirow{8}{*}{$\begin{array}{c}\text { (Tsui i sar., } \\
\text { 2014) }\end{array}$} & 0,55 \\
\hline & BP3 & & 0,541 & & 0,03 \\
\hline & BP4 & & 0,496 & & $1,30 \times 10^{-3}$ \\
\hline & BP8 & & 0,083 & & 0,02 \\
\hline & HMS & & 0,154 & & 0,20 \\
\hline & OD-PABA & & 0,505 & & 1,68 \\
\hline & EHMC & & 0,224 & & 0,56 \\
\hline & 4-MBC & & 0,207 & & 0,10 \\
\hline \multirow{4}{*}{6} & BP1 & \multirow{4}{*}{ Otpadna voda } & 0,418 & \multirow{4}{*}{$\begin{array}{c}\text { (O’Malley i sar., } \\
\text { 2020) }\end{array}$} & 1,49 \\
\hline & BP3 & & 1,340 & & 0,070 \\
\hline & BP4 & & 3,090 & & $8,11 \times 10^{-3}$ \\
\hline & 4-MBC & & 0,691 & & 0,35 \\
\hline \multirow{3}{*}{7} & $\mathrm{OC}$ & \multirow{3}{*}{ Sediment } & $0,128^{a}$ & & 2,25 \\
\hline & EHMC & & $0,045^{a}$ & (Amine I sar., & 1,71 \\
\hline & OD-PABA & & $0,017^{a}$ & & 0,47 \\
\hline & $\mathrm{OC}$ & & $0,373^{a}$ & & 6,56 \\
\hline 8 & EHMC & Sediment & $0,0075^{a}$ & (capela I sar., & 0,29 \\
\hline & BP3 & & $0,0072^{\mathrm{a}}$ & & 1,09 \\
\hline & 4-MBC & & $0,017^{a}$ & & 0,20 \\
\hline 9 & EHMC & Sediment & $0,047^{a}$ & (Dalom I sal., & 1,79 \\
\hline & BP3 & & $0,054^{a}$ & & 8,18 \\
\hline & BP3 & & 0,182 & & 2.6 \\
\hline & IAMC & & 0,200 & & n.d. ${ }^{b}$ \\
\hline 10 & 4-MBC & Marcka unda & 1,225 & (Benedé i sar., & n.d. \\
\hline 10 & $\mathrm{OC}$ & IVorska voda & 0,187 & 2014) & 0.47 \\
\hline & EHMC & & 0,144 & & 0.48 \\
\hline & ES & & 0,680 & & n.d. \\
\hline & BP3 & & 0,879 & & 12.56 \\
\hline & IAMC & & 0,645 & & n.d. \\
\hline & 4-MBC & & 0,758 & & n.d. \\
\hline 11 & $\mathrm{OC}$ & Morska voda & 0,440 & (Roman i sar., & 1.1 \\
\hline & EHMC & & 1,187 & 2011) & 3.96 \\
\hline & ES & & 1,222 & & n.d. \\
\hline & HMS & & 1,030 & & n.d. \\
\hline
\end{tabular}

a koncentracije UV filtera u sedimentima izražene su u $\mu \mathrm{g} / \mathrm{g}$

${ }^{b}$ n.d.- nedovoljno toksikoloških podataka za izračunavanje PNEC vrednosti

U okviru istraživanja rađenog u Ujedinjenom Kraljevstvu (Kasprzyk-Hordern i sar., 2009), uzorak 4, zabeležene su veoma visoke vrednosti koncentracija derivata benzofenona (BP1, BP2, BP3 i BP4) u rečnoj vodi, nizvodno od postrojenja za prečišćavanje otpadnih voda. Na osnovu vrednosti $R Q$, prisustvo BP1, BP2 i BP3 u datim koncentracijama predstavlja visok ekološki rizik, dok BP4 u datoj koncentraciji predstavlja umeren ekološki rizik, što znači da postoji potencijal neželjenih efekata efluenta otpadnih voda. Naime, postrojenja za prečišćavanje otpadnih voda nisu dovoljno efikasna za uklanjanje 
UV filtera iz vode, što za posledicu ima ispuštanje efluenta sa visokim sadržajem ovih supstanci u rečne vodotokove. U uzorku 5 uzorkovanom u efluentu iz postrojenja u Hong Kongu (Tsui i sar., 2014) najviše koncentracije UV filtera zabeležene su u slučaju BP3, BP4 i OD-PABA. Visok ekološki rizik predstavlja prisustvo OD-PABA, dok je u slučaju BP3 i BP4 ekološki rizik nizak. U uzorku 6 efluenta otpadne vode iz Australije nakon sekundarnog tretmana (O'Malley i sar., 2020), derivat benzofenona BP1 se nalaze u koncentraciji koji predstavlja visok ekološki rizik. $R Q$ vrednost u slučaju 4-MBC iznosi 0,35 što ukazuje na potencijalan umereno negativan uticaj ovog jedinjenja, u datim koncentracijama, na određene vodene organizme u recipijentu.

Analizom uzorka 7 sedimenta na mestu ispusta otpadne vode u reku (Amine i sar., 2012) potvrđeno je prisustvo OC i EHMC u koncentracijama koje imaju negativan ekološki uticaj, dok je ekološki rizik usled prisustva OD-PABA u uzorku umeren. U uzorku 8 sedimenta sa peščane plaže u Portugalu, u toku meseca septembra (Capela i sar., 2019) visok ekološki rizik zabeležen je usled prisustva OC i BP3, a prisustvo EHMC u datoj koncentraciji predstavlja umeren ekološki rizik. Prisustvo BP3 i EHMC u uzorku 9 sedimenta iz Kolumbije, uzetom na ušću reke Magdalene u Karipsko more, (Barón i sar., 2013) predstavlja visok ekološki rizik po životnu sredinu, dok je u slučaju 4-MBC rizik umeren.

Prilikom izračunavanja koeficijenta ekološkog rizika usled prisustva UV filtera u morskoj vodi korišćene su PNEC vrednosti za morsku vodu dobijene AF metodom. Usled nedovoljnog broja toksikoloških podataka bilo je moguće izračunati PNEC vrednosti samo za BP3, OC i EHMC. Na osnovu RQ vrednosti, može se zaključiti da postoji visok ekološki rizik usled prisustva BP3 u morskoj vodi za vreme sezone kupanja (uzorci 10 i 11). Koncentracije OC i EHMC u uzorku broj 10 (Benedé i sar., 2014) uzetom sa ostrva Majorka, plaža Pamlira, ukazuju na umeren ekološki rizik, dok je ekološki rizik usled prisustva ovih jedinjenja u uzorku broj 11 (Román i sar., 2011) uzetom sa gradske plaže u Španiji visok. Za ostale UV filtere koji su određivani u navedenim studijama nije bilo moguće izračunati $R Q$ vrednost, ali se na osnovu visokih koncentracija u kojima se nalaze i dostupnih toksikoloških podataka može pretpostaviti da imaju negativan ekološki uticaj.

\section{ZAKLJUČAK / CONCLUSION}

Cilj ovog rada je procena ekološkog rizika usled prisustva odabranih organskih UV filtera u vodi i sedimentima. Procena ekološkog rizika izvršena je na osnovu podataka iz različitih studija, vezanih za rezultate monitoringa ovih supstanci u vodi i sedimentima, kao i na osnovu podataka o njihovoj toksičnosti po vodene organizme.

$\mathrm{Na}$ osnovu podataka iz studija, koje su analizirane u ovom radu, može se zaključiti da su u uzorcima iz životne sredine najviše zastupljeni organski UV filteri BP3, BP4 i EHMC. Na brojnim lokacijama detektovane su koncentracije koje ukazuju na visok ekološki rizik. Visoke koncentracije UV filtera detektovane su na kupalištima, a pokazan je i sezonski karakter, odnosno viši ekološki rizik u letnjem periodu. Najviše vrednosti koeficijenta rizika usled prisustva odabranih organskih UV filtera detektovane su u otpadnim vodama, kao i na mestima ispusta otpadne vode u recipijent. Visoke koncentracije detektovane su i u uzorcima rečnih voda i sedimenta čije je uzorkovanje vršeno nizvodno od mesta ispusta otpadnih voda.

$\mathrm{Na}$ osnovu ovih koncentracija i vrednosti koeficijenta rizika, UV filteri predstavljaju visok ekološki rizik po određene delove životne sredine, a posebno su ugrožena mesta na kojima dolazi do ispusta neadekvatno tretiranih otpadnih voda.

\section{Zahvalnica / Acknowledgement}

Ovaj rad podržalo je Ministarstvo prosvete, nauke i tehnološkog razvoja Republike Srbije (Broj ugovora. 451-03-68/2020-14/200287 i 451-03-68/2020-14/200 135).

\section{LITERATURA / REFERENCES}

[1] Amine, H., Gomez, E., Halwani, J., Casellas, C., Fenet, H. (2012), UV filters, ethylhexyl methoxycinnamate, octocrylene and ethylhexyl dimethyl PABA from untreated wastewater in sediment from eastern Mediterranean river transition and coastal zones. Mar. Pollut. Bull. 64, 2435-2442. https://doi.org/10.1016/j.marpolbul.2012.07.051

[2] Barón, E., Gago-Ferrero, P., Gorga, M., Rudolph, I., Mendoza, G., Zapata, A.M., Díaz-Cruz, S., Barra, R., Ocampo-Duque, W., Páez, M., Darbra, R.M., Eljarrat, E., Barceló, D. (2013), Occurrence of hydrophobic organic pollutants (BFRs and UVfilters) in sediments from South America. Chemosphere, 92, 309-316. https://doi.org/10.1016/ j.chemosphere.2013.03.032

[3] Benedé, J.L., Chisvert, A., Salvador, A., SánchezQuiles, D., Tovar-Sánchez, A. (2014), Determination of UV filters in both soluble and particulate fractions of seawaters by dispersive liquid-liquid microextraction followed by gas chromatographymass spectrometry. Anal. Chim. Acta, 812, 50-58. https://doi.org/10.1016/j.aca.2013.12.033

[4] Bratkovics, S., Wirth, E., Sapozhnikova, Y., Pennington, P., Sanger, D. (2015), Baseline monitor- 
ing of organic sunscreen compounds along South Carolina's coastal marine environment. Mar. Pollut. Bull., 101, 370-377. https://doi.org/10.1016/ j.marpolbul.2015.10.015.

[5] Capela, D., Vila, M., Llompart, M., Dagnac, T., García-Jares, C., Alves, A., Homem, V. (2019), Footprints in the sand - Assessing the seasonal trends of volatile methylsiloxanes and UV-filters. Mar. Pollut. Bull. 140, 9-16. https://doi.org/10. 1016/j.marpolbul.2019.01.021

[6] Carve, M., Nugegoda, D., Allinson, G., Shimeta, J. (2020), A systematic review and ecological risk assessment for organic ultraviolet filters in aquatic environments. Environ. Pollut. 115894. https://doi.org/10.1016/j.envpol.2020.115894

[7] Cunha, S.C., Trabalón, L., Jacobs, S., Castro, M., Fernandez-Tejedor, M., Granby, K., Verbeke, W., Kwadijk, C., Ferrari, F., Robbens, J., Sioen, I., Pocurull, E., Marques, A., Fernandes, J.O., Domingo, J.L. (2018), UV-filters and musk fragrances in seafood commercialized in Europe Union: Occurrence, risk and exposure assessment. Environ. Res. 161, 399-408. https://doi.org/10.1016/j.envres.2017.11.015

[8] Gago-Ferrero, P., Díaz-Cruz, M.S., Barceló, D. (2012), An overview of UV-absorbing compounds (organic UV filters) in aquatic biota, Anal Bioanal Chem, 404, 2597-2610. https://doi.org/10.1007/s00216-012-6067-7

[9] Kasprzyk-Hordern, B., Dinsdale, R.M., Guwy, A.J. (2009), The removal of pharmaceuticals , personal care products, endocrine disruptors and illicit drugs during wastewater treatment and its impact on the quality of receiving waters. Water Res., 43(2), 363-380. https://doi.org/10.1016/j.watres.2008.10.047

[10] Lukić, J., Đurkić, T., Jovanović, L., Aleksić, G., Onjia, A. (2020), Total petroleum hydrocarbons distribution and health risk assessment of soil in the Niš railway junction. Ecologica, 27(100), 597604.

[11] Moeder, M., Schrader, S., Winkler, U., Rodil, R. (2010), At-line microextraction by packed sorbentgas chromatography-mass spectrometry for the determination of UV filter and polycyclic musk compounds in water samples. J. Chromatogr. A, 1217, 2925-2932.

https://doi.org/10.1016/j.chroma.2010.02.057

[12] NORMAN (2021). Ecotoxicology Database. https://www.norman-network.com/nds/ecotox/ (last accessed: February 21, 2021
[13] O’Malley, E., O’Brien, J.W., Verhagen, R., Mueller, J.F. (2020), Annual release of selected UV filters via effluent from wastewater treatment plants in Australia. Chemosphere, 247, 1-7. https:// doi.org/10.1016/j.chemosphere.2020.125887

[14] Radomirović, M., Ćirović, Ž., Maksin, D., Bakić, T., Lukić, J., Stanković, S., Onjia, A. (2020), Ecological Risk Assess-ment of Heavy Metals in the Soil at a Former Painting Industry Facility. Front. Environ. Sci., 8, 560415.

https://doi.org/10.3389/fenvs.2020.560415

[15] Ramos, S., Homem, V., Alves, A., Santos, L. (2016), A review of organic UV-filters in wastewater treatment plants. Environ. Int. 86, 24-44. https://doi.org/10.1016/j.envint.2015.10.004

[16] Román, I.P., Chisvert Alberto, A., Canals, A. (2011), Dispersive solid-phase extraction based on oleic acid-coated magnetic nanoparticles followed by gas chromatography-mass spectrometry for UV-filter determination in water samples. J. Chromatogr. A, 1218, 2467-2475. https://doi.org/10.1016/j.chroma.2011.02.047

[17] Santos, A.J.M., Miranda, M.S., Esteves da Silva, J.C.G. (2012), The degradation products of UV filters in aqueous and chlorinated aqueous solutions. Water Res. 46, 3167-3176. https://doi.org/10.1016/j.watres.2012.03.057

[18] Tanić, M., Janković Mandić, L., Ćujić, M., Onjia, A., Dinić, D., Dragović, S. (2018), Human health risk assessment due to natural radionuclides in soil affected by coal combustion: A case study from the surroundings of the largest thermoelectric power plant in Serbia. Ecologica, 25(89), 5-11.

[19] Tsui, M.M.P., Leung, H.W., Lam, P.K.S., Murphy, M.B. (2014). Seasonal occurrence, removal efficiencies and preliminary risk assessment of multiple classes of organic UV filters in wastewater treatment plants. Water Res. 53, 58-67. https://doi.org/10.1016/j.watres.2014.01.014

[20] Wu, M. Hong, Li, Jian, Xu, G., Ma, L. Dan, Li, Jia Jun, Li, Jin Song, Tang, L. (2018). Pollution patterns and underlying relationships of benzophenone-type UV-filters in wastewater treatment plants and their receiving surface water. Ecotoxicol. Environ. Saf. 152, 98-103. https://doi.org/10.1016/j.ecoenv.2018.01.036

[21] Wu, M. Hong, Xie, D. Guo, Xu, G., Sun, R., Xia, X. Yu, Liu, W. Long, Tang, L. (2017). Benzophenonetype UV filters in surface waters: An assessment of profiles and ecological risks in Shanghai, China. Ecotoxicol. Environ. Saf. 141, 235-241. https://doi.org/10.1016/j.ecoenv.2017.03.013. 